CALVIN WELLS: TWO MEDIAEVAL CASES OF MALIGNANT DISEASE

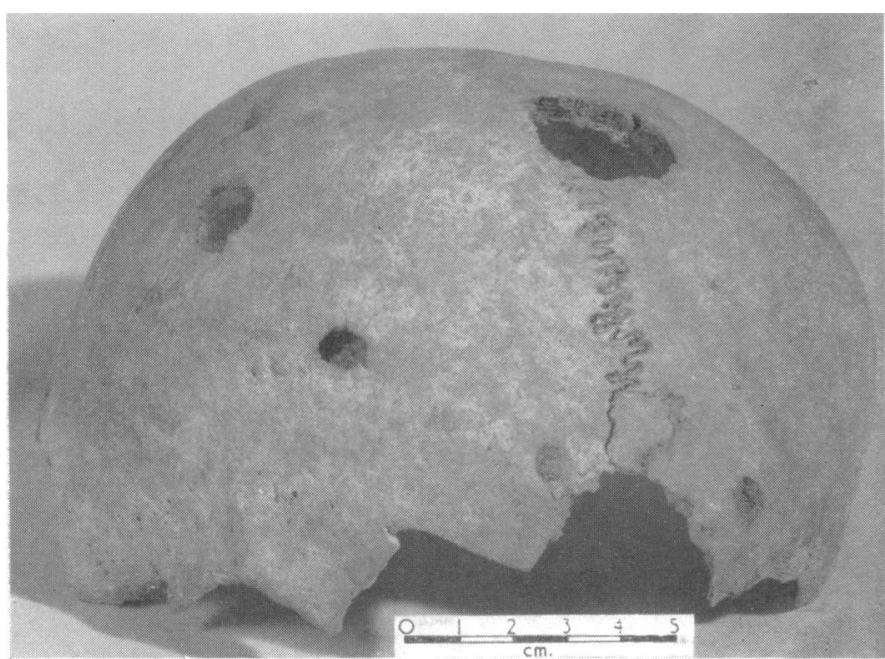

FIG. 1

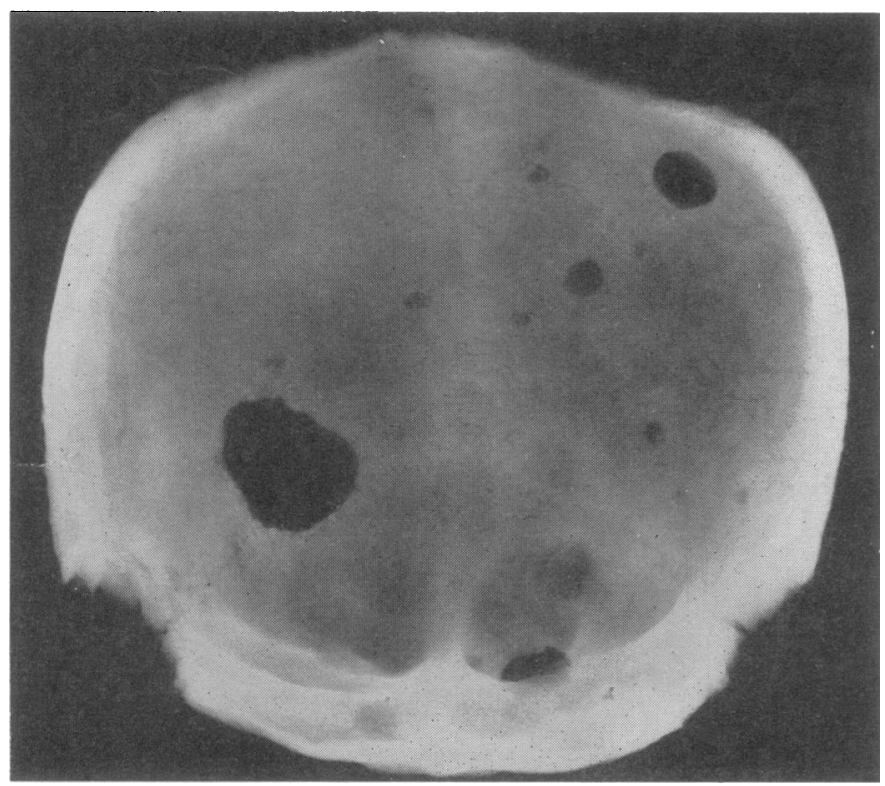

FIG. 2

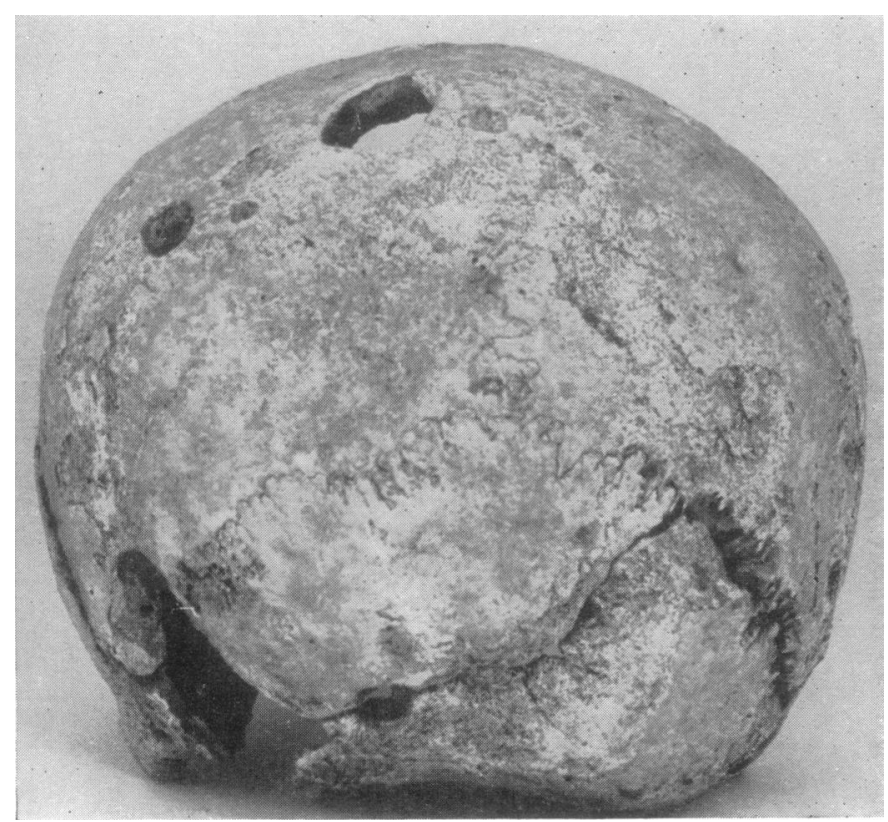

FIG. 3

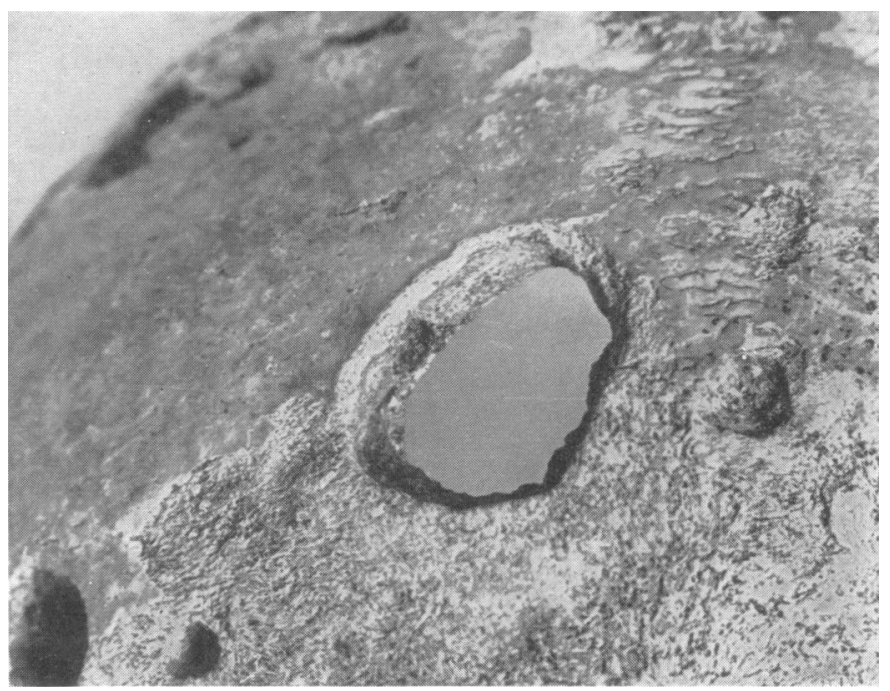

FIG. 4

FIG. 1.-Photograph of Stonar skull, showing several perforations-some partial, some complete.

FIG. 2.-Radiograph of Stonar skull, showing additional scattered foci of destruction starting to erode the diploë.

FIG. 3.-Photograph of Ipswich skull. Two complete and several partial perforations can be seen.

FIG. 4.-Photograph of Ipswich skull, showing a profile of the largest perforation.

FIG. 5.-Radiograph of Ipswich skull, showing additional diffuse foci in the diploë.

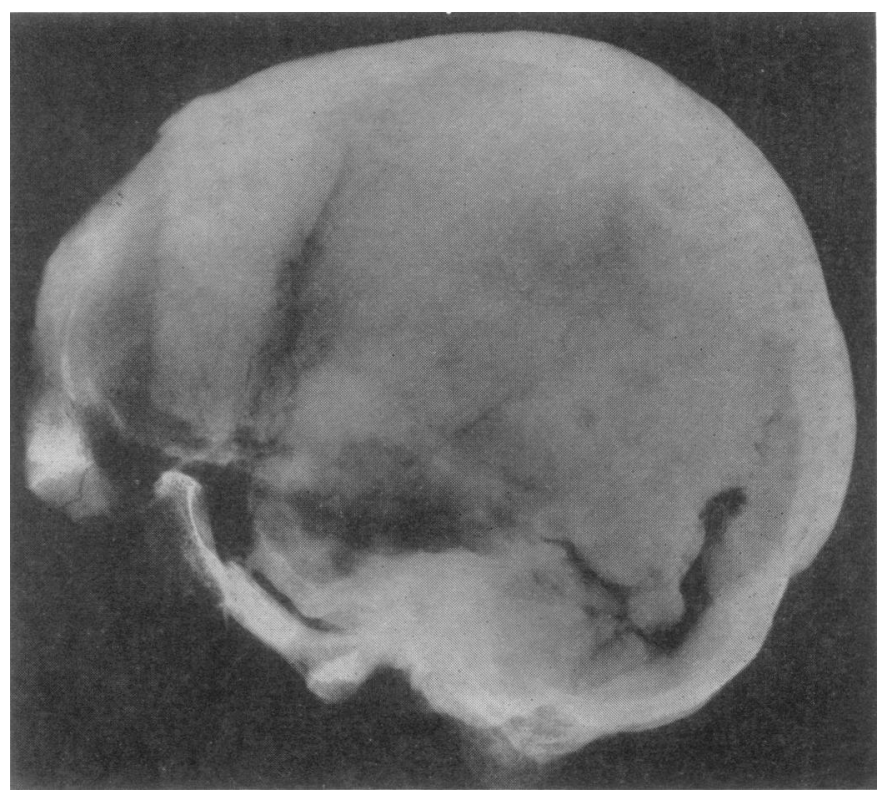

FIG. 5 
by the first course; the second was cleared at the end of the second course of $750 \mathrm{mg}$. every six hours for one month, but the third only after a third course of $5 \mathrm{~g}$. a day for six weeks. Salm. typhi is an intracellular parasite, and it may be that treatment must be prolonged till cell death exposes the organism to the action of the drug. All that can be said from the present series is that a high daily dose of ampicillin, supplemented by probenecid and continued for three months, seems to produce very encouraging results.

Ampicillin appears to be not quite so effective as chloramphenicol in the treatment of the acute case of typhoid fever (Patel, 1964), though it would be interesting to know the final bacteriological results in a series of patients properly followed up. Relapses, both clinical and bacteriological, occur fairly often in patients treated with chloramphenicol, and it might be rewarding to give a course of ampicillin in the convalescent stage after the chloramphenicol, and to compare the bacteriological results with those obtained by chloramphenicol alone. And finally, although the chemoprophylaxis of any infection is a far from simple affair, and may result only in the prolongation of the incubation period rather than the eradication of the infection, a bactericidal drug is less likely to fail in prophylaxis than a bacteriostatic one (Petersdorf and Woodward, 1961). Ampicillin is bactericidal and its use in household contacts of typhoid fever might produce results comparable with those in contacts of smallpox treated by $\mathrm{N}$-methylisatin- $\beta$-thiosemi- carbazone (Bauer et al., 1963), though only a long-controlled trial could produce acceptable evidence.

\section{Summary}

Eight chronic typhoid carriers were treated with ampicillin for three months. All became abruptly negative as soon as treatment began, and seven have remained negative for a year. The eighth carrier has relapsed twice but has responded to further treatment with ampicillin on each occasion.

Supplies of ampicillin were generously provided by the manufacturers, Beecham Research Laboratories. I am indebted to Dr. O. P. W. Robinson, of Beecham Research Laboratories, for much comment and advice during the trials.

\section{REFERENCES}

Bauer, D. J., Vincent, L. St., Kempe, C. H., and Downie, A. W. (1963). Lancet, 2, 494.

Bokkenhauser, V. (1964). Amer. F. Publ. Hlth, 54, 477.

Patel, K. M. (1964). Brit. med. 7., 1, 907.

Petersdorf, R. G., and Woodward,' T. E. (1961). \%. Pediat., 58, 153 Public Health Laboratory Service Working Party (1961). \%. Hys. (Lond.), 59, 231 .

Troy, Patricia (1964). Brit. med. 7., 1, 1252.

\title{
Two Mediaeval Cases of Malignant Disease
}

\author{
CALVIN WELLS,* F.R.A.I., PH.D., M.R.C.S.
}

[With Special Plate]

Brit. med. F., 1964, 1, 1611-1612

A principal concern of palaeopathologists is not only to identify the occurrence of specific diseases in ancient populations but also to estimate the frequency with which these diseases occur. This is because the pathology of any community is always a reflection of its total environment and way of life ; hence the study of a group's morbidity will invariably give information about its living conditions. Often we find that an ancient population was afflicted by lesions which are identical with those found to-day: osteoarthritis, fractures, periostitis, paradontal abscesses, etc. Sometimes we can detect only a slight (albeit significant) difference between the ancient and modern incidence of these diseases.

Outstanding exceptions to this are malignant conditions, especially carcinomata. To-day these growths and their secondary deposits in bone are extremely common. In early burial grounds they are remarkably rare. Only three or four cases of indubitable carcinoma have been recognized among the tens of thousands of ancient Egyptian mummies and skeletons which have been examined. Hardly a score of such cancers have been identified from all the cemeteries of the preRenaissance world.

It is not my intention to review these cases here, though some very remarkable facts are disclosed by them. For example, despite the very small number involved several appear to have been nasopharyngeal in origin. One of the Romano-Egyptian cases described by Elliot Smith and Dawson (1924) was so

- Castle Museum, Norwich. situated, likewise another of about 3000 B.c. (Wells, 1963), another from precolumbian Chavina, Peru (Wells, 1964), a possible Neolithic one from Maiden Castle, Dorset (Goodman and Morant, 1940), and a strongly probable one from Tepe Hissar, Iran, c. 3000 B.c. (Krogman, 1940 ; Wells, 1964). In my Egyptian example the primary nasopharyngeal destruction of bone was obvious and was accompanied by many secondary deposits throughout the skull. No postcranial bones were present.

In view of the rarity with which cancer has been diagnosed in early peoples it is important to record all specimens which are discovered. Eventually a pattern of types and distribution may emerge. Two closely similar examples are described here.

\section{Case 1}

This consists of a single piece of a cranial vault (Special Plate, Fig. 1). It comprises approximately the posterior two-thirds of both parietals and the nearly complete squamous part of the occipital ; although no more of the body has been recovered the preservation of this fragment is excellent. It came from the churchyard of Stonar Church, near Sandwich, Kent, and the balance of evidence suggests that it is of fourteenth- or fifteenth-century date.

The obtrusive feature of this calva is the presence of a number of holes in it. These are undoubtedly pathological, not artifacts such as are sometimes found as the result of post-mortem damage by soil erosion, insect attack, or other causes. Three of these beles penetrate right through the bone, three involve only the diploë and 
outer table, and three more have eroded only the diploë and inner table. They vary in size from $4 \mathrm{~mm}$. up to $28 \mathrm{~mm}$. in diameter, are circular or slightly elliptical, and have undercut edges involving a wider destruction of diploë than of compact bone.

The margins are sharp and no surrounding area of periostitis is present, but an irregular band of endosteitis, up to about $1 \mathrm{~cm}$. wide, can be seen in the cavity of the skull around the largest perforation-that in the right parietal. This "berm" has a finely reticulated appearance which arose during life but is now somewhat ambiguous owing to slight post-mortem erosion. It is difficult to detect any real evidence of healing in these lesions; however, a lowgrade bony reaction seems to have occurred at the diploic face of some of the openings. They are quite unlike any infective condition, either syphilitic or pyogenic, and nothing about them points to a traumatic origin. Congenital lacunae and numerous other possible causes of cranial perforation can also be excluded. The whole appearance of this calva suggests secondary deposits of malignant growth. Radiography confirms this and reveals (Special Plate, Fig. 2) that several foci of neoplastic erosion are present in the diploë but have not yet broken through either the inner or outer tables of the skull.

As is so often the case in palaeopathology, where the invaluable aid of a clinical history is absent, the precise diagnosis is fraught with uncertainty. Great wariness is needed. The likeliest choice would seem to be either multiple myelomatosis or secondary deposits of a carcinoma. Several early examples of multiple myeloma have been described, including one of Bronze Age date from a Pyrenean site (Fuste, 1955) and two in precolumbian American Indians. One of these (Williams, Ritchie, and Titterington, 1941) was a 10-year-old child ; in the other, an old man (Ritchie and Warren, 1932), extensive deposits were present throughout the skeleton and the appearance of the skull resembles very closely indeed that of the Stonar specimen. But it must be recognized that, despite their overall good state of preservation, half a millennium of inhumation has somewhat blunted the nuances of diagnostic discrimination, whether macroscopic or radiographic, in both examples.

\section{Case 2}

This consists of an isolated calva, excavated from the site of St. James's Leper House, Ipswich, Suffolk. Its probable date range is twelfth to fifteenth century (Special Plate, Fig. 3).

Again the outstanding feature is a number of perforations in the skull. Like those of the Stonar bone, which they closely resemble, they are obviously pathological. Four penetrate the entire thickness of the cranial vault, three involve only the diploë and inner table, two only the diploë and outer table. They are circular or elliptical in shape, with sharp undercut margins (Special Plate, Fig. 4), and vary from 3 to $22 \mathrm{~mm}$. in diameter. A radiograph (Special Plate, Fig. 5) again reveals the presence of numerous foci of diploic invasion which have not penetrated either table of the skull.

Here, also, the likely diagnosis is either multiple myeloma or secondary carcinoma, but although we can be sure that these were malignant lesions the final uncertainty is too great to justify a dogmatic decision.

\section{Discussion}

The lesions of these two calvae are in all respects so nearly identical that the two specimens must be seen as a single problem in diagnosis. A minor difference is that the trace of endosteitis around the largest Stonar orifice appears to have no counterpart anywhere in the Ipswich skull. But it cannot be definitely excluded, because surface damage from postmortem soil erosion somewhat masks the original appearance in parts of the latter skull. In both calvae the exposed diploic tissue shows a few small areas where the open spongy texture of the bone is partly smoothed over. This suggests that some attempt has been made to seal off the neoplastic encroachment. No effective reaction has been achieved, but the fact that these traces of it are detectable may indicate that myelomatosis is rather more probable than carcinoma.

With nothing more than two incomplete cranial vaults we cannot determine the ages at death with any certainty. Nowadays the evidence of sutural union is little valued. In both the Stonar and the Ipswich skulls endocranial fusion is just beginning in the obelionic part of the sagittal suture ; elsewhere the sutures are unfused. All we can say is that this would make them on balance somewhat more likely to be young individuals than old ones-but it would not exclude a centenarian. If this evidence is worth considering it, too, would increase the likelihood of myelomatosis, which is rather more prone to affect young adults than is carcinoma. But it should also be remarked that even such a cautious generalization as this may be overbold and may cease to apply in specific places and epochs. The nasopharyngeal growths referred to above are rare to-day in Western Europe, but they are the commonest of all cancers in parts of East Africa, where they typically attack children and young adolescents, with rapidly fatal results. We are still a long way from knowing what the state of affairs was, in this respect, in mediaeval and earlier times.

The Ipswich calva poses an additional problem of great interest in view of its discovery on the site of an old leper hospital. During life it is probable that these deposits of growth were producing swellings under the scalp and may even have fungated through it (though in the absence of infective periostitis this seems unlikely). The indurated swellings under the scalp, however, may have been not unlike some of the lesions of lepromatous leprosy. It is possible that a misdiagnosis was made and the patient was believed to suffer from lepra. But this can only be guesswork. The presence of this skull in an old leper establishment may merely mean that the building continued in use for general diseases long after leprosy itself was on the decline.

\section{Summary}

Two isolated mediaeval calvae are described, from Kent and Suffolk, which show typical malignant lesions of an almost identical appearance. Each has features suggestive of secondary carcinoma or of multiple myelomatosis. It is felt that the total evidence is insufficient to permit a firm discrimination between these possible diagnoses.

My thanks are due to Mr. G. C. Dunning, of the Inspectorate of Ancient Monuments, for permission to describe the Stonar case (now in the care of the Ministry of Public Building and Works), and to Mr. Norman Smedley, Curator, Ipswich Museum, for allowing me to record the second specimen, which is in his care. My thanks are also due to Ilford Ltd. for their courtesy in radiographing these specimens.

\section{REFERENCES}

Fuste, M. (1955). Trab. Inst. Sahagún. Antrop., 14, 109.

Goodman, C. N., and Morant, G. M. (1940). Biometrika, 31, 295 Krogman, W. M. (1940). Bull. Hist. Med., 8, 28.

Ritchie, W. A and Warren, S. L. (1932). Amer. F. Roentgenol., 28, 622. Smith, G. Elliot, and Dawson, W. R. (1924). Egyptian Mummies. Allen and Unwin, London.

Allen and Unwin, London.
Wells, Calvin (1963). f. Laryng., 77, 261.

Wells, Calvin (1963). F. Laryng., 77, 261.

Williams, G. D., Ritchie, W. A., and Titterington, P. F. (1941). Amer. 7. Roentgenol., 46, 351 . 